\title{
10
}

\section{Soft tissue injections}

\author{
Luís P.B.S. Inês MD
}

Rheumatologist

José António P. da Silva* MD, PhD

Consultant Rheumatologist and Professor of Rheumatology

Hospitais da Universidade de Coimbra, 3000-075 Coimbra, Portugal

Soft tissue rheumatism includes a wide spectrum of common lesions of the tendons, enthesis, tendon sheaths, bursae, ligaments and fasciae as well as nerve compression syndromes. Studies on the pathogenesis of these lesions do not support a major role for inflammation, thus questioning the rationale for glucocorticoid injections. This chapter reviews current indications for local glucocorticoid injections and available evidence on its efficacy, as well as contraindications and potential risks. Randomised controlled studies of good methodological quality are rare and there is limited scientific evidence to support the superiority of glucocorticoid injections over alternative treatments.

The basic principles of the glucocorticoid injection method are outlined, together with a description of the practical procedure for the more common conditions.

Key words: soft tissue rheumatism; treatment; glucocorticoid injection.

Periarticular soft tissue rheumatic disorders include a wide spectrum of localised lesions of the tendons, enthesis, tendon sheaths, bursae, ligaments and fasciae as well as nerve compression syndromes. They are extremely common in daily practice and result in significant morbidity and socioeconomic impact. These aspects, together with their tendency to chronicity and recurrence, make the treatment of these conditions an important health care issue.

Local injection of corticoglucocorticoid agents is commonly used for this purpose. This is usually perceived as a simple, safe and effective procedure. In this chapter we will explore the rationale and, in particular, the evidence base for their use. Basic principles of the glucocorticoid injection method are outlined and the most common procedures are described.

\footnotetext{
* Corresponding author. Fax: + 35I 239401045.

E-mail address: jdasilva@ci.uc.pt (J.A.P. da Silva).
}

I52 I-6942/\$ - see front matter (C) 2004 Elsevier Ltd. All rights reserved. 


\section{CONTEXT AND RATIONALE}

Clinically, soft tissue lesions are commonly classified as acute (up to 2 weeks in duration), subacute (2-4 weeks) and chronic (over 6 weeks). Early intervention in soft tissue lesions is based on patient education, aimed at resolving the injury and preventing chronicity and recurrence. ${ }^{1-3}$ Proposed measures include correction of aggravating factors, relative rest and appropriate exercise. Initial control of pain may be achieved through analgesics and non-glucocorticoidal anti-inflammatory drugs (NSAIDS), ice, ultrasound and transcutaneous electrical nerve stimulation, although evidence to support these approaches is scarce. ${ }^{4}$

Soft tissue injections with glucocorticoids are commonly reserved for chronic cases, after an adequate trial of other conservative measures for at least 2 months has failed. ${ }^{\prime}$ Local anaesthetic is frequently mixed with the glucocorticoid for soft tissue injections, with several potential advantages: reduction of discomfort during the procedure, confirmation of the diagnosis by the immediate abolition of pain and an increased injection volume, where needed for wider dispersion. ${ }^{5}$ Occasionally, as in trigger points, local anaesthetic may be injected alone, without glucocorticoid. ${ }^{6}$ The main soft tissue conditions usually considered amenable to local glucocorticoid injection are listed in Table I.

The rationale for the use of corticoglucocorticoids in these disorders presumes that there is an inflammatory process and that the control of inflammation will lead to the resolution or improvement of the disorder. However, evidence from histopathological, biochemical and molecular studies does not support a major role of inflammation in these conditions. ${ }^{1,7,8}$

Painful tendon lesions are usually named 'tendinitis', a term that implies an inflammatory process. In most cases, this is thought to be the result of repetitive microtrauma causing repeated microstrain below the failure threshold of the tendon. ${ }^{4}$ Such continued tendon overload leads to injury to collagen fibrils, matrix and microvasculature, accompanied by inflammation of the paratenon, which becomes fibrotic and thickened. The role and relevance of inflammation at the early stage is not clear. ${ }^{7} \mathrm{It}$ is conceivable that the degree of inflammation may vary with time, justifying differences in the rhythm of pain and in the response to glucocorticoid injection. However, this hypothesis remains to be proven. In the final stages, pathology consists mostly of tendon degeneration or 'tendinosis', without signs of intratendinous inflammation. ${ }^{7-10}$ The entire tendon architecture is deranged, including collagen, tenocytes and extracellular matrix, with associated degenerative and reparative

Table I. Common indications for soft tissue glucocorticoid injection.

\begin{tabular}{ll}
\hline Anatomical region & Soft tissue disorder \\
\hline $\begin{array}{l}\text { Shoulder } \\
\text { Elbow }\end{array}$ & Rotator cuff tendinitis; subacromial bursitis; bicipital tenosynovitis \\
Wrist and hand & Olecranon bursitis; lateral and medial epicondylitis \\
& Carpal tunnel syndrome; De Quervain's tenosynovitis; extensor and flexor \\
Hip & Trochanteric bursitis; iliopsoas bursitis; ischiogluteal bursitis; addutor \\
& tendinitis; meralgia paraesthetica \\
Knee & Pes anserinus lesions and anserine bursitis; patellar tendinitis \\
Ankle and foot & Tarsal tunnel syndrome; posterior tibialis tenosynovitis; plantar fasciitis; \\
& Morton's interdigital neuroma \\
\hline
\end{tabular}


processes. Therefore, the term tendinopathy,' seems more appropriate than 'tendinitis,' for describing these conditions.

\section{EFFICACY}

Although soft tissue injections are very popular among rheumatologists and have stood the 'proof of time,' there is a remarkable paucity of controlled data to support their efficacy. Randomised controlled trials are scarce and their interpretation is frequently hindered by methodological issues, such as poor definition of cases, inclusion of heterogeneous study populations, small sample sizes, unsuitable outcome measures, short term follow up, inadequate blinding and lack of true placebo. ${ }^{1,4,11}$

Evaluation of efficacy may be hampered by unreliability of diagnosis and accuracy of injection. Even in a specialist's hands, up to $70 \%$ of periarticular injections may be misplaced. ${ }^{12}$ Increasing use of ultrasonography and magnetic resonance imaging for diagnosis and ultrasound-guided injection may improve this. ${ }^{13}$ Placement of glucocorticoids under ultrasound guidance is, of course, much more precise than blind injections. ${ }^{14,15}$ It is intuitive to expect ultrasound-guided injections to be more effective and safe. However, demonstration of this potential advantage by adequate studies is still scarce. ${ }^{16}$ The current scientific evidence on the efficacy of blind soft tissue glucocorticoid injection is reviewed below.

\section{Rotator cuff tendinopathy}

Buchbinder et al in a Cochrane systematic review ${ }^{4}$, identified 10 controlled trials comparing glucocorticoid injection for rotator cuff tendinopathy with placebo and other active interventions, including NSAIDS, physiotherapy and acupuncture. Four out of seven placebo-controlled trials ${ }^{17-23}$ reported efficacy of glucocorticoid injections. Results from two of these trials could be pooled, showing a small benefit of injection over placebo at 4 weeks, with regard to pain and function. Pooled results of three trials comparing subacromial glucocorticoid injection to oral NSAID ${ }^{17,20,24}$ showed no benefit of one treatment over the other at 4 or 6 weeks of follow-up. Based upon these findings, there is little evidence to either support or refute a superior efficacy of glucocorticoid injections for rotator cuff tendinopathy. ${ }^{4}$

\section{Lateral epicondylitis}

Assendelft et al performed a systematic review of randomised controlled trials on the effectiveness of glucocorticoid injection for lateral epicondylitis. ${ }^{25}$ They analysed 12 trials, including ten placebo-controlled studies, but the overall methodological quality was poor to moderate. Pooled results from nine trials favoured glucocorticoid injection in the short term (up to 6 weeks) but showed no significant differences in long term effects. In a randomised controlled trial carried out by Hay et al comparing glucocorticoid injection to NSAIDs and analgesics ${ }^{26}$, outcome was favourable to injection after 4 weeks, with no difference between groups at I year.

\section{Olecranon bursitis}

In a retrospective study by Weinstein et $\mathrm{al}^{27}, 47$ patients with traumatic olecranon bursitis were treated by bursal aspiration with or without intrabursal glucocorticoid 
injection. Bursitis resolved in almost all cases, but much more rapidly in those submitted to glucocorticoid injection. However, injected patients suffered complications, such as infection (three cases in 25 patients) and skin atrophy (five cases in 25 patients), which were not seen in those submitted to aspiration alone.

\section{De Quervain's tenosynovitis}

Anderson et al in a non-controlled study ${ }^{28}$, submitted 56 cases of De Quervain's tenosynovitis to glucocorticoid injections and assessed effectiveness by follow-up for an average of 4.2 years. At 6 weeks post-injection, $8 \mathrm{I}$ and $13 \%$ of patients experienced complete or partial clinical response, respectively, while $58 \%$ maintained complete resolution for the duration of follow-up and $27 \%$ needed reinjections for recurrence. Ultimately, $90 \%$ experienced a good response to injection and only $10 \%$ required surgery. Other short-term and retrospective studies also report benefit. We are not aware of any controlled prospective trials.

\section{Trigger finger}

In a double blind, placebo-controlled trial, Lambert et $\mathrm{al}^{29}$ compared glucocorticoid injection plus local anaesthetic to anaesthetic alone in 41 patients with trigger finger. Significant improvement was experienced by $60 \%$ of the glucocorticoid group, compared with $16 \%$ of controls at I month of follow-up. A similar trial involving 24 patients, also showed benefit of glucocorticoid injection at 3 weeks' follow-up. ${ }^{30}$ Anderson and Kaye, in a non-controlled study ${ }^{31}$, treated 77 trigger fingers in 58 patients by glucocorticoid injection and followed them up for an average of 4.6 years. In the long term, a single injection was successful in $61 \%$ of the cases and a further $27 \%$ had recurrences that responded well to multiple injections, while $12 \%$ were referred for surgery.

\section{Carpal tunnel syndrome}

Most studies on local glucocorticoid injection for carpal tunnel syndrome (CTS) are either retrospective or non-randomised. " ' Dammers et al ${ }^{32}$ compared glucocorticoid injection in 30 patients with placebo injection in another 30 , following a randomised controlled design. The results demonstrated significant improvement in the glucocorticoid versus placebo group, at I month post-injection. A longer duration of relief, up to I year, is suggested by the open extension of this study and other noncontrolled trials. Celiker et $\mathrm{al}^{33}$ performed an unblinded, randomised controlled trial comparing local glucocorticoid injection versus oral NSAID and wrist splinting in 23 patients with CTS. The results demonstrated clinical improvement in both treatment groups at 8 weeks of follow-up, with no superiority for one treatment over the other. Subjects with milder CTS may be more responsive to glucocorticoid injection than those with a more severe condition, according to one prospective trial. ${ }^{34}$

\section{Trochanteric bursitis}

In an open study of glucocorticoid injection for trochanteric bursitis ${ }^{35}, 77$ and $61 \%$ of 75 patients reported improvement at $I$ and 26 weeks of follow-up, respectively. 


\section{Achilles' tendinopathy}

In a double-blind randomised controlled trial, DaCruz et a ${ }^{36}$ found no benefit of glucocorticoid plus anaesthetic injection over anaesthetic alone in 28 subjects.

In conclusion, the efficacy of local corticoglucocorticoid injections in the treatment of periarticular soft tissue lesions has been the object of a limited number of trials, frequently affected by methodological limitations. Overall, there is some evidence that glucocorticoid injections may be faster in relieving symptoms than alternative treatments for some conditions. There is no evidence that this benefit may be longlasting for the majority of these disorders. There is a clear need for further trials of good methodological quality to settle this question.

\section{CONTRAINDICATIONS AND RISKS}

There are few contraindications to soft tissue corticoglucocorticoid injections, as shown in Table 2. In addition, they are very safe, as long as the indications, contraindications and technical recommendations are respected. Potential adverse effects are listed in Table 3. Their actual incidence is unknown.

Patients should always be asked about previous allergic reactions to local anaesthetics and glucocorticoids. Moderate pain at the injection site is common. An inflammatory flare, characterised by aggravation of pain, swelling and redness for up to 48 hours following the injection occurs occasionally and may represent a reaction to glucocorticoids crystals. ${ }^{37}$ A reaction persisting beyond 48 hours requires evaluation for possible infection and other complications. Risk of infection is estimated to be very ${ }^{l o w}{ }^{38}$ when using sterile 'no-touch' techniques.

Misplaced injections may result in tendon rupture and nerve damage. For this reason, injections should not be performed inside the tendon, i.e. against resistance. Loading the tendon after infiltration and multiple glucocorticoid injections may also predispose to rupture. The Achilles tendon seems especially prone to such accidents. If dysesthesiae arises on attempted injection of a nerve tract, for example in the carpal tunnel, the needle should be repositioned, to avoid nerve damage.

Subcutaneous tissue atrophy and skin depigmentation are more frequently reported following superficial glucocorticoid injections, as for subcutaneous bursae and De Quervain's tenosynovitis. These may be more likely if long-acting glucocorticoids, such as triamcinolone hexacetonide, are given.

Absorption of glucocorticoids after local injection may be sufficient to produce systemic effects, such as temporary suppression of the hypothalamic-pituitary-adrenal axis. However, systemic side effects are rare.

Table 2. Contraindications to soft tissue glucocorticoid injections.

\begin{tabular}{ll}
\hline Absolute & Infection in locality \\
& Serious allergy to local anaesthetics or glucocorticoids \\
Relative & Anticoagulation or bleeding diathesis \\
& Systemic infection \\
\hline
\end{tabular}


Table 3. Adverse reactions after soft tissue glucocorticoid injection.

\begin{tabular}{ll}
\hline Immediate & Pain at the injection site \\
& Inflammatory flare reaction \\
& Ecchymosis at the injection site \\
& Infection \\
& Vasovagal reaction \\
& Anaphylaxis \\
Late & Subcutaneous tissue atrophy \\
& Skin depigmentation \\
& Tendon rupture \\
& Nerve damage \\
\hline
\end{tabular}

\section{GENERAL TECHNICAL RECOMMENDATIONS}

Published recommendations for soft tissue injections are based on personal experience and anecdote more than on evidence. Even for conditions that have been more extensively studied, such as tennis elbow, a systematic review of 12 randomised controlled trials failed to reach any conclusions with respect to the most suitable glucocorticoid, the most adequate dose, injection volume or interval. ${ }^{25}$ Common practice is remarkably variable between centres and practitioners with respect to almost all aspects of the procedures: environment, antiseptic care, use and volume of anaesthetic, type and dose of glucocorticoid, rest after injection, etc. ${ }^{39}$

The technical recommendations presented here have the same limitations: they are based on our personal experience, informed by the published recommendations of others $^{40-45}$ and only occasionally supported by hard evidence, in the rare instances where this is available.

\section{Preparation}

Local injection should be based as much as possible on a clear diagnosis and careful consideration of the risks, benefits and alternative approaches. The patient should be asked for informed consent and accept the post-injection recommendations. The practitioner should have good knowledge of the local anatomy, indications and contraindications and technical details of the procedure. Enough experience should be gained before independent performance.

\section{Materials}

- Carefully wash your hands before starting preparation of drugs

- Use short or medium-acting glucocorticoid preparations for most cases (methylprednisolone acetate will usually be a good choice)

- A suitable volume of local anaesthetic (e.g. lignocaine 1\%) may be mixed in certain conditions

- Make sure that the anaesthethic solution is clear and devoid of any debris before collecting it in the syringe

- Always use sterile disposable needles and syringes

- Select the smallest possible diameter of needle that can reach the lesion 


\section{Asepsis}

Use a no-touch technique: swab your hands and the patient's skin with iodine or $70 \%$ ethanol. Do not touch the site of injection or the needle after swabbing

\section{Technique}

- Patient and practitioner should be in a comfortable position

- Always try to support the hand holding the syringe, so that movements are finely controlled.

- Mark the site of injection with pencil or a pressure mark

- Surface anaesthesia may be necessary for sensitive patients

- Cross the skin quickly as this is the most sensitive area

- Advance until the tip of the needle is inside the lesion

- Always draw back on the syringe before injecting, to make sure that the needle is not in a vascular structure

- Cover the periphery of a tendon using a fan technique with half-withdrawals and reinsertions: inject a small volume, redraw the needle towards the skin and reintroduce it in another direction. Inject again and repeat these steps until the lesion is covered.

Please note that injections should be done into the periphery of tendons and not in their interior. Advance the tip of the needle into the tendon and test the resistance to the embolus: it should be high if the tip of the needle is inside the tendon. Redraw the needle slowly while pressing the embolus. When resistance goes down, the tip of the needle should be in the periphery of the tendon: that is where the glucocorticoid should be placed.

\section{Post-injection care}

- Cover the injection site with a sterile strap

- Ask the patient to gently move the area in order to spread the fluid.

- Ask the patient to contact you in case of any suggestion of infection or other significant adverse event

Advice regarding rest after the injection is variable. Absolute rest of the injected area for 24 hours and limited use for $2-4$ weeks is a common recommendation that we have followed with satisfactory results. Several authors suggest that local injections should not be repeated before 6 weeks and that no more than three injections should be done on the same site. Such recommendations seem based on fear of tendon rupture, but we are unaware of any sound evidence to support their value.

\section{Choice of glucocorticoid preparations}

Table 4 shows some characteristics of the most common injectable preparations of glucocorticoids. Low solubility is associated with longer duration of action. Long-acting fluorinated glucocorticoids, namely triamcinolone hexacetonide, which are frequently preferred for intra-articular injections are considered by some authors to be inadequate for periarticular injections, due to a higher risk of atrophy in the 
Table 4. Common injectable glucocorticoid preparations.

\begin{tabular}{lcll}
\hline & Potency & Concentration $(\mathrm{mg} / \mathrm{ml})$ & Solubility $(\% w t / v o l)$ \\
\hline Hydrocortisone acetate & $\mathrm{I}$ & 25 & 0.002 \\
Prednisolone acetate & 4 & 25 & 0.001 \\
Methylprednisolone acetate & 5 & $20,40,80$ & 0.001 \\
Triamcinolone acetonide* & 5 & 10,40 & 0.004 \\
Betametasone sodium & 25 & 6 & $\mathrm{NA}$ \\
posphate/acetate* & & 4 & 0.01 \\
Dexamethasone phosphate* & 25 & 20 & 0.0002 \\
Triamcinolone hexacetonide* & 5 & &
\end{tabular}

Source: adapted from Gray et al 1981. ${ }^{38}$ *Fluorinated compounds. NA, not applicable.

surrounding tissues. ${ }^{40,41}$ Others, however, recommend triamcinolone for soft tissue injections. ${ }^{4}$

Methylprednilone acetate (MPA) is the most commonly recommended glucocorticoid for soft tissue injections and will be taken as the reference standard in this chapter.

\section{Needle placement and ultrasound}

Despite the fact that rheumatologists feel very confident and satisfied with their own injection practice and results, controlled studies show that, even in the hands of specialists, glucocorticoid is frequently placed outside the target area. In the study carried out by Eustace et al ${ }^{12}$ regarding shoulder injections, only $29 \%$ of the subacromial and $42 \%$ of the intra-articular injections were correctly placed by experienced practitioners. Similar results were found with regard to De Quervain's tenosynovitis. ${ }^{47}$ These studies also demonstrated that the outcome was closely related to the accuracy of the injection.

Such observations underline the need for careful consideration of the technique, but raise considerable uncertainty in the face of the numerous variations that can be found in published recommendations and, even more, in clinical practice. The suggestions given below reflect our preferences and current practice.

\section{SITE-SPECIFIC TECHNIQUES}

\section{Subacromial space}

The following techniques may be used to treat rotator cuff tendinopathy and subacromial bursitis.

\section{Material}

- 5-10 ml syringe

- $40 \times 0.7 \mathrm{~mm}(22 \mathrm{G})$ gauge needles

- $40 \mathrm{mg}$ MPA (I ml)

- I\% lignocaine (3-4 ml) 


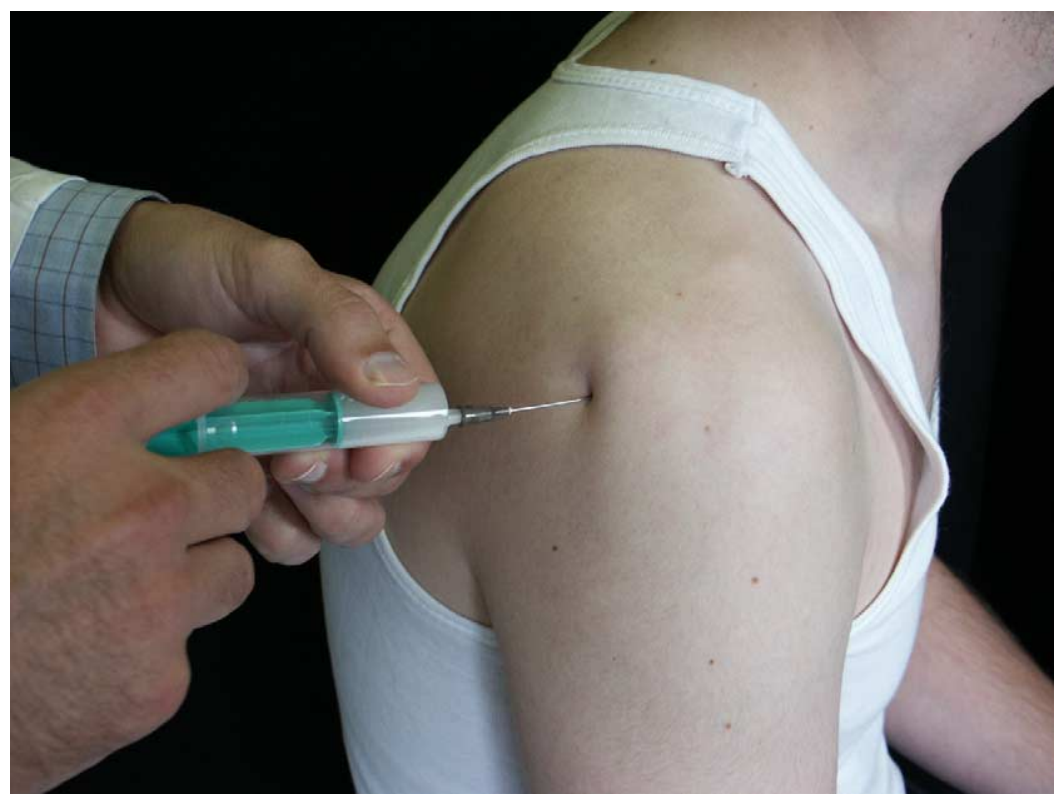

Figure I. Injection of the subacromial space: posterolateral approach.

\section{Posterolateral approach}

Use the posterior tip of the acromion as an anatomical reference. Insert the needle into the space between the acromion and the humeral head (Figure I) and drive it in an anteriorly-directed course toward the coracoid process. Inject under the acromion. Resistance to drug delivery should be minimal.

\section{Lateral approach}

Palpate the gap between the acromion and the head of the humerus on the tip of the shoulder. Insert the needle into this space (Figure 2) aiming it slightly upwards and inject under the acromion. There should be little or no resistance to the plunger.

\section{Anterior approach}

This is a personal adaptation with good, although anecdotal, results. The shoulder is kept in forced internal rotation (hand behind the back). The greater tuberosity of the humerus with the supraspinatus tendon can now be felt anteriorly to the acromion. The subacromial bursa covers these structures. The most tender point is identified and marked. Enter the skin perpendicularly to the surface (Figure 3) and inject several spots in the periphery of the tendon. 


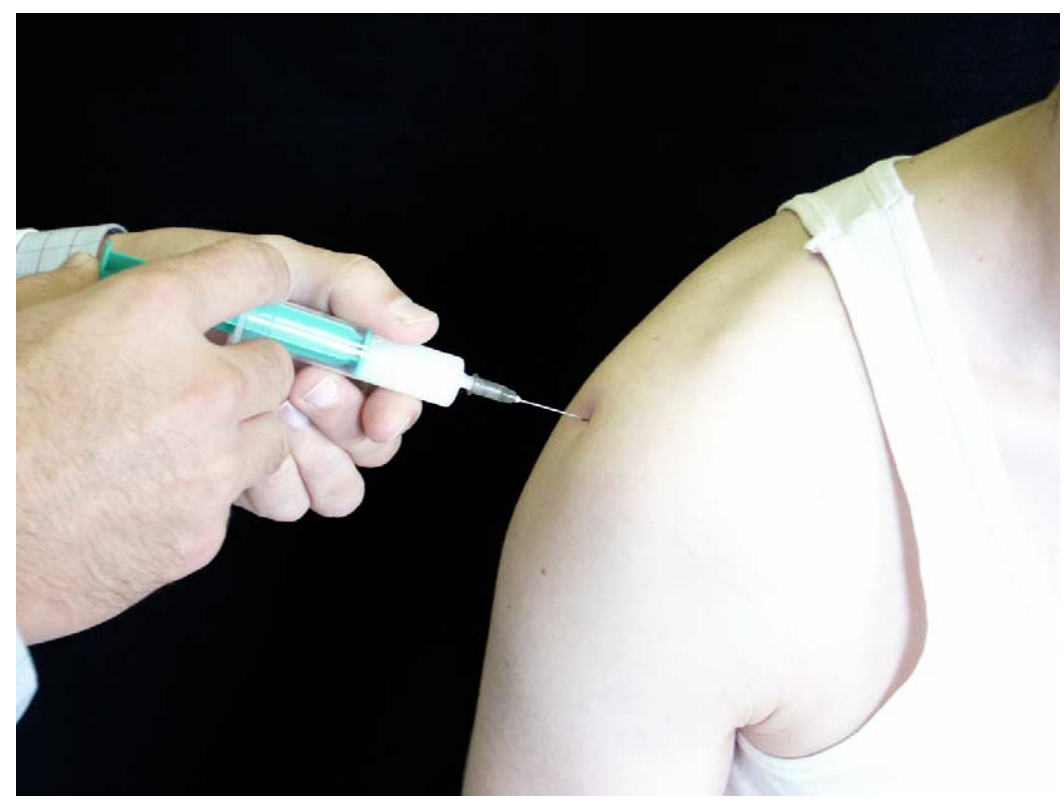

Figure 2. Injection of the subacromial space: lateral approach.

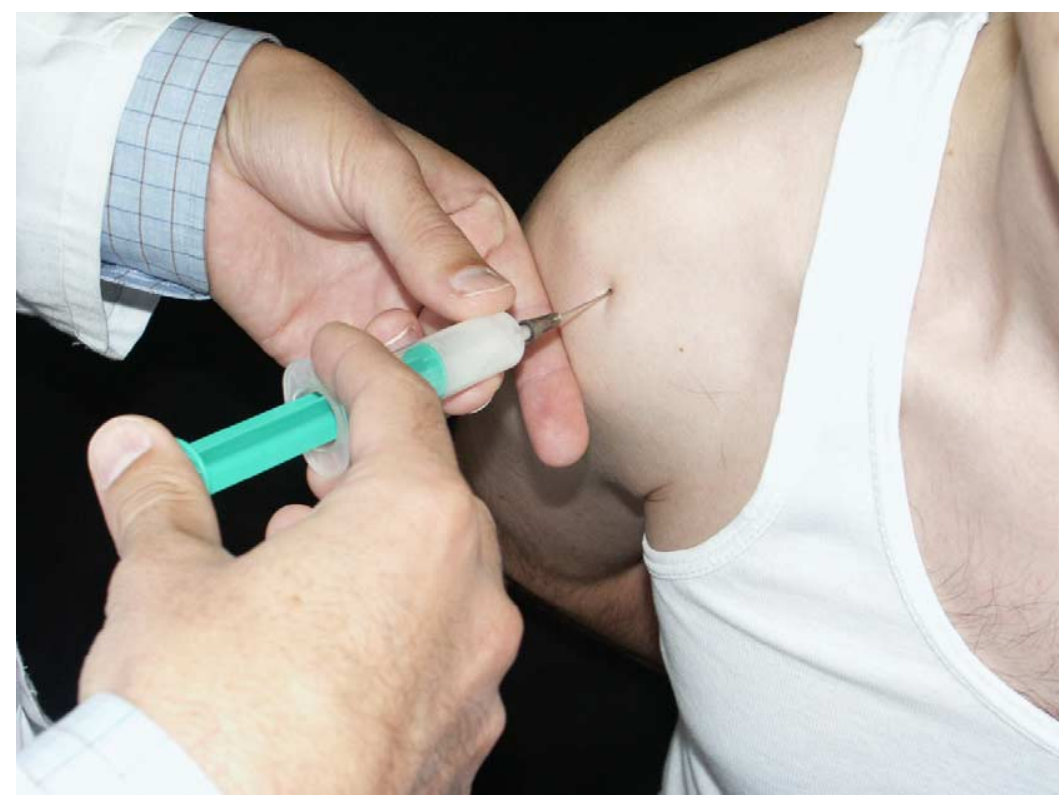

Figure 3. Injection of the subacromial space: anterior approach. 


\section{Biceps tendon sheath}

\section{Material}

- 2-5 ml syringe

- $40 \times 0.7 \mathrm{~mm}(22 \mathrm{G})$ gauge needles

- $40 \mathrm{mg}$ MPA (I ml)

- I\% lignocaine $(2 \mathrm{ml})$

The biceps tendon can be easily palpated in the anterior aspect of the shoulder, in its groove. Identify the most tender spot, enter the skin perpendicularly to the surface and progress with the needle until the bone (Figure 4). Inject about I $\mathrm{ml}$ of the mixture following the general recommendations. Redraw the needle about $2 \mathrm{~cm}$ and redirect it to the tendon sheath about $2 \mathrm{~cm}$ above the previous spot and inject again. Repeat the procedure $2 \mathrm{~cm}$ below the original spot.

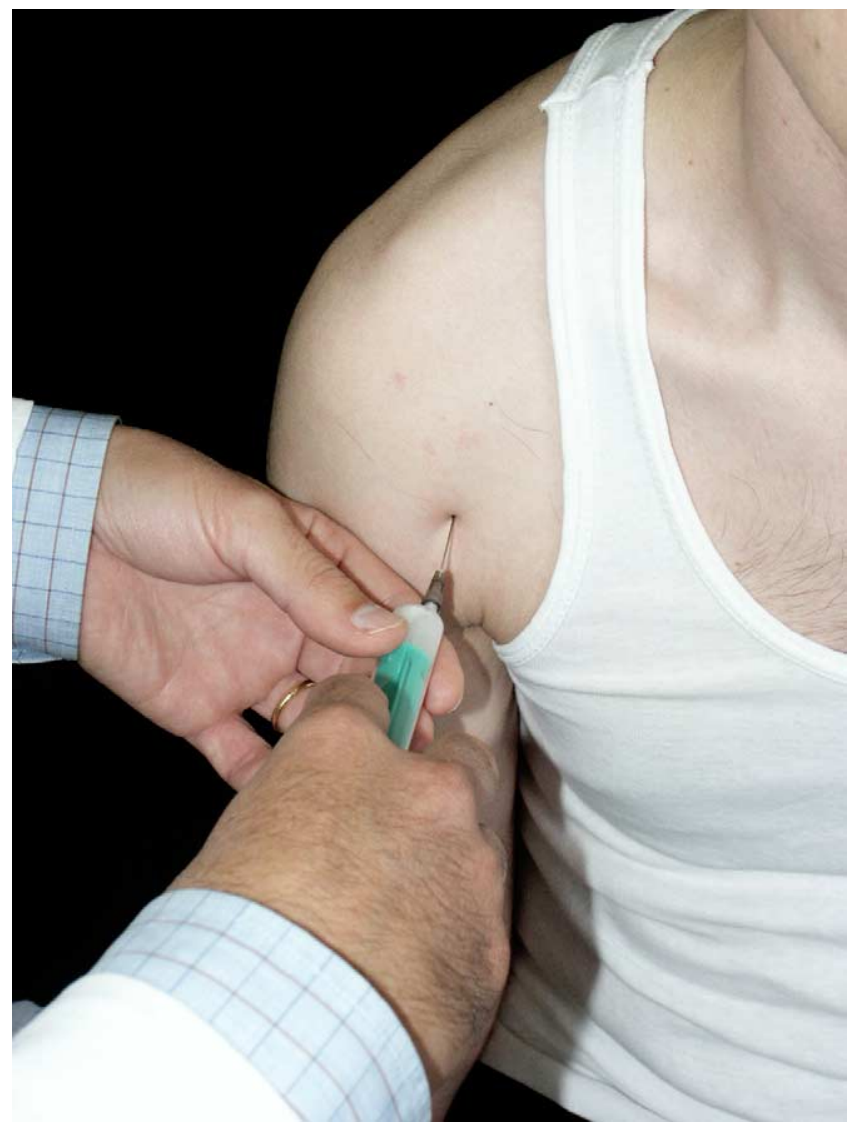

Figure 4. Injection of the biceps tendon sheath. 


\section{Lateral and medial epicondyle}

\section{Material}

- $2 \mathrm{ml}$ syringe

- $20 \times 0.5 \mathrm{~mm}(25 \mathrm{G})$ gauge needles

- 20-40 mg MPA (0.5-I ml)

The elbow is semiflexed and supported. The needle is inserted into the site of maximal tenderness until it reaches bone (Figure 5). Slightly withdraw the needle and infiltrate both deeply and superficially using a fan technique as suggested in the general recommendations. Warn the patient of probable exacerbation of pain for 24-48 hours. Be aware of the ulnar nerve when injecting the medial epicondyle. Some authors recommend that, contrary to the general recommendation, glucocorticoids should, in these lesions, be placed inside the tendons, as close as possible to their insertions on bone. This requires the use of a small volume of glucocorticoid, without anaesthetic, which is injected under pressure.

\section{Carpal tunnel}

\section{Material}

- $2 \mathrm{ml}$ syringe

- $20 \times 0.5 \mathrm{~mm}(25 \mathrm{G})$ gauge needles

- 20-40 mg MPA (0.5-I ml)

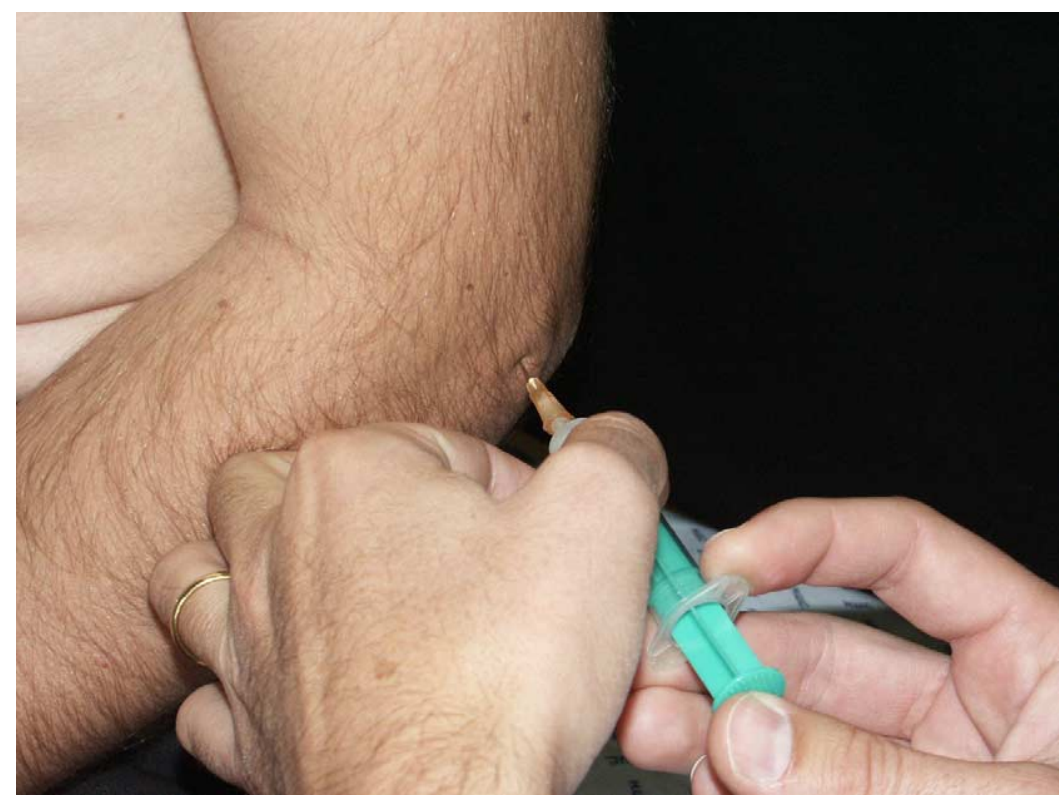

Figure 5. Injection of the lateral epicondyle. 


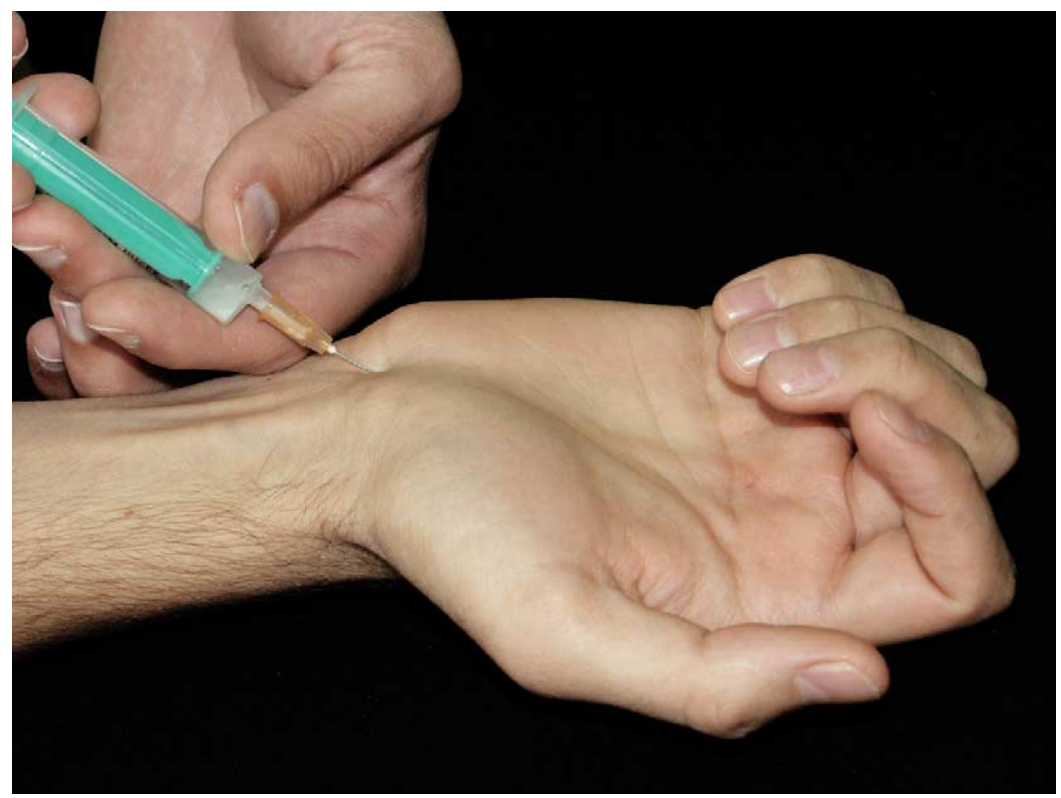

Figure 6. Injection of the carpal tunnel.

Identify the palmaris longus tendon by asking the patient to flex the wrist against resistance. Enter the skin medially to this tendon at the distal palmar crease in the wrist. Keep the syringe at an angle of $45^{\circ}$ to the forearm and inject the glucocorticoid about $\mathrm{I}-2 \mathrm{~cm}$ below the skin (Figure 6). There should be no resistance to injection and no pain or paraesthesia in the median nerve territory.

\section{De Quervain's tenosynovitis}

\section{Material}

- $2 \mathrm{ml}$ syringe

- $20 \times 0.5 \mathrm{~mm}(25 \mathrm{G})$ gauge needles

- 20-40 mg MPA (0.5-l ml)

- I\% lignocaine ( $\mathrm{l} \mathrm{ml}$ )

Identify the site of maximal tenderness on the tendons sheaths. Keeping the thumb under resisted abduction, enter the skin from the hand at an angle of about $30^{\circ}$, aligned with the tendon and aiming the tip of the needle towards the peritendinous space (Figure 7). Inject at different spots around the tendon, avoiding any resistance.

\section{Flexor tendon sheaths}

\section{Material}

- $2 \mathrm{ml}$ syringe

- $20 \times 0.5 \mathrm{~mm}(25 \mathrm{G})$ gauge needles

- $20 \mathrm{mg}$ MPA (0.5-I ml) 


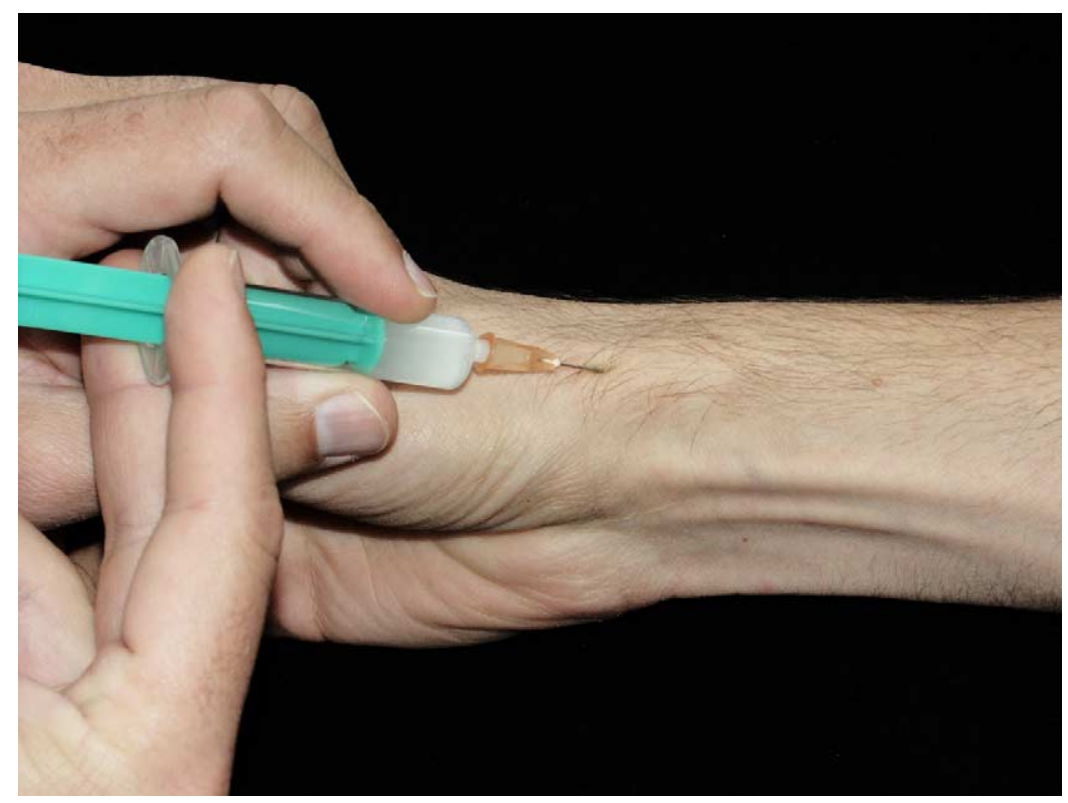

Figure 7. Injection of de Quervain's tenosynovitis.

Identify the site of maximal tenderness (or around a palpable nodule) on the tendon sheaths on the palmar aspect of the metacarpal heads or proximal phalanx (usually proximally to the metacarpal crease). Enter the skin from the fingers at an angle of about $45^{\circ}$, aligned with the tendon and aiming the tip of the needle to the peritendinous space (Figure 8). Check that the needle is touching the tendon: passive motion of the finger will induce movement in the needle. Redraw the needle slightly until resistance against injection is lost: place the glucocorticoid as close to the tendon as possible.

\section{Greater trochanter}

\section{Material}

- $10 \mathrm{ml}$ syringe

- $50 \times 0.8 \mathrm{~mm}(2 \mathrm{I} \mathrm{G})$ gauge needles

- 40-80 mg MPA (I-2 ml)

- I\% lignocaine $(3-5 \mathrm{ml})$

In some patients tenderness is limited to a small area on the lateral aspect of the greater trochanter, suggesting trochanteric bursitis. More frequently, however, in our experience, maximal tenderness is found along the muscle insertions in the superior and posterior borders of the great trochanter, requiring larger injection volumes and, frequently, more than one injection site. The patient should lie on the opposite side to the lesion. Carefully identify the sites of maximal tenderness and mark points on the skin that will allow best access to them in a fan-like technique. Enter the skin and advance the needle until it reaches bone (Figure 9). Redraw the needle slightly and inject 


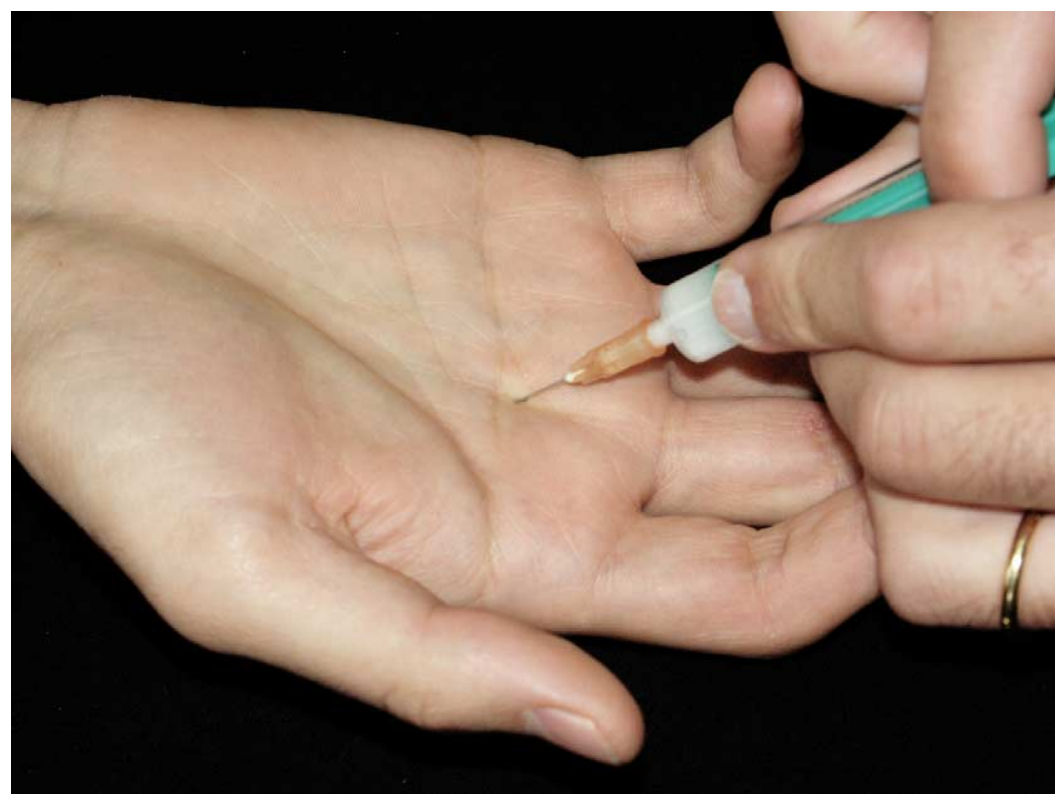

Figure 8. Injection of flexor tendon sheath.

a small volume. Make injections at other painful sites, about $2 \mathrm{~cm}$ from each other, using a fan technique.

\section{Adductor tendinopathy}

\section{Material}

- $5 \mathrm{ml}$ syringe

- $50 \times 0.8 \mathrm{~mm}(2 \mathrm{l} \mathrm{G})$ gauge needles

- $40 \mathrm{mg}$ MPA (I ml)

- I\% lignocaine (I-2 ml)

Carefuly identify the site of maximal pain in the insertion of the adductors close to the pubic symphysis. Inject around the tendon.

\section{Ischiogluteal bursitis}

\section{Material}

- $5 \mathrm{ml}$ syringe

- $50 \times 0.8 \mathrm{~mm}(2 \mathrm{l} \mathrm{G})$ gauge needles

- $40 \mathrm{mg}$ MPA (I ml)

- I\% lignocaine (I-2 ml)

Locate the site of maximum tenderness while the patient is lying on his back or side. Inject into and around this area. 


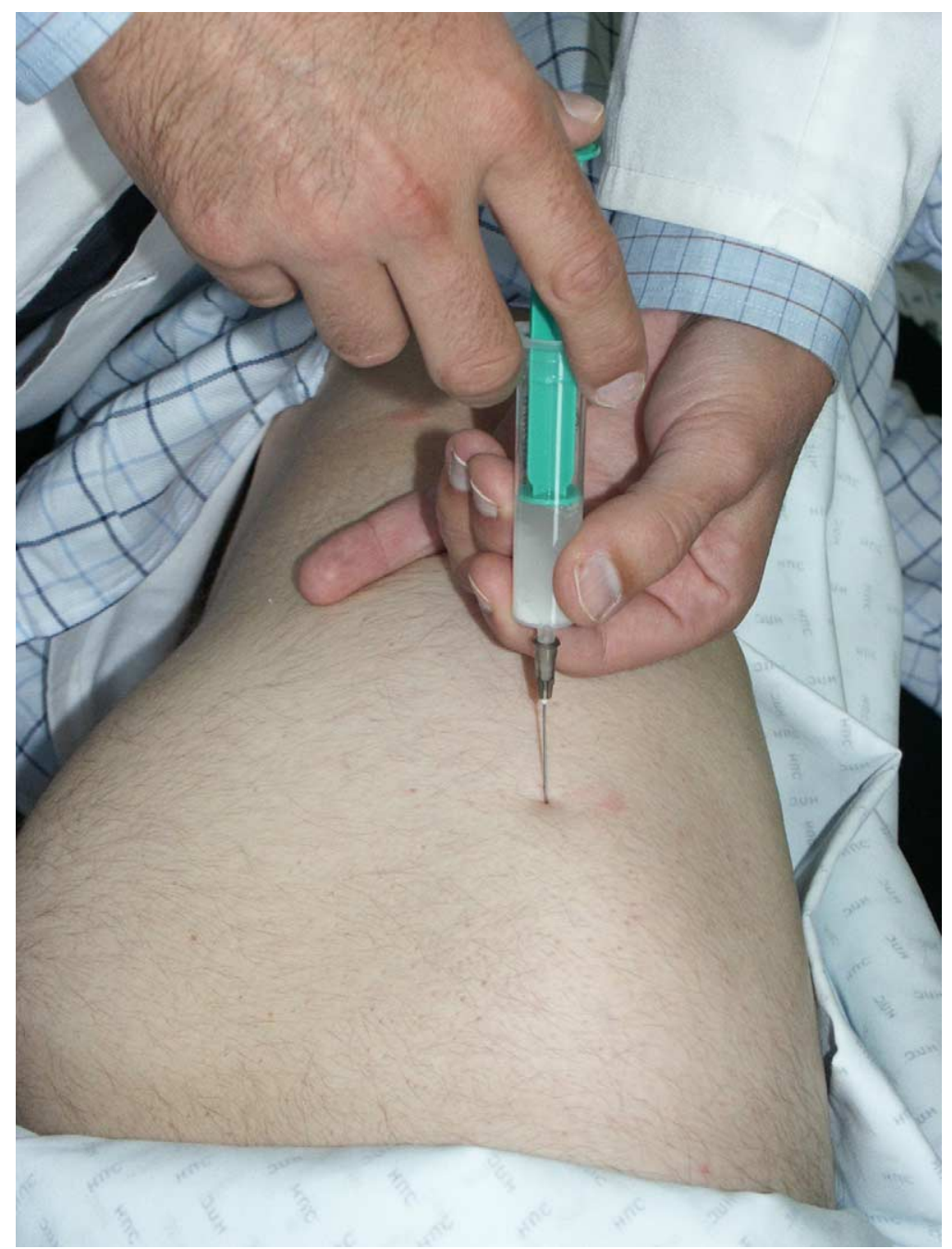

Figure 9. Injection of the greater trochanter area.

\section{Meralgia paraesthetica}

\section{Material}

- $5 \mathrm{ml}$ syringe

- $50 \times 0.8 \mathrm{~mm}(2 \mathrm{l} \mathrm{G})$ gauge needles

- $40 \mathrm{mg}$ MPA (I ml)

- $\mathrm{I} \%$ lignocaine $(\mathrm{I}-2 \mathrm{ml})$

The injection should be made at one of two sites: either around $\mathrm{I} \mathrm{cm}$ below and medially to the anterior superior iliac crest or $10 \mathrm{~cm}$ below this point. We usually select 
the most tender of these sites. A positive Tinel sign reinforces the choice. The needle is inserted perpendicular to the skin and the injection performed at about $2 \mathrm{~cm}$ of depth.

\section{Pes anserinus}

\section{Material}

- $10 \mathrm{ml}$ syringe

- $50 \times 0.8 \mathrm{~mm}(2 \mathrm{IG})$ gauge needles

- 40-80 mg MPA (l-2 ml)

- I\% lignocaine $(3-5 \mathrm{ml})$

In our experience, pain in the medial aspect of the knee is frequently related to marked tenderness in the tendons of the isquio-tibial muscles at the level of the medial femur condyle or just above it. Injection into these tender sites is frequently rewarding for the patient and the physician. The patient should lie on the side of the lesion, with the affected knee slightly flexed. Carefully identify the sites of maximal tenderness and mark points in the skin that will allow best access to them in a fan-like technique (Figure 10). Enter the skin and advance the needle until it reaches bone. Redraw the needle slightly and inject a small volume. Address the painful structures using a fan technique.

Occasionally pain is confined to a limited area in the anteromedial aspect of the proximal tibia, suggesting true anserine bursitis. The technique for this follows the same principles. Injection volumes are accordingly smaller.

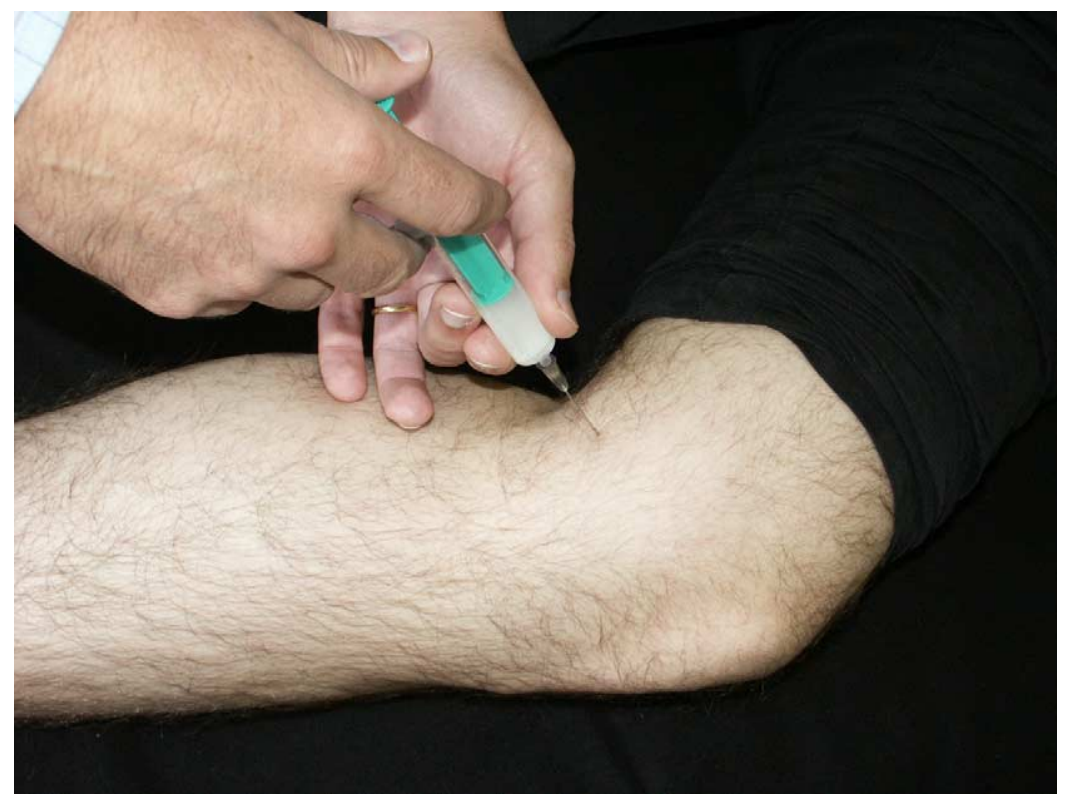

Figure 10. Injection of the pes anserinus. 


\section{Illiotibial band}

\section{Material}

- $5 \mathrm{ml}$ syringe

- $20 \times 0.5 \mathrm{~mm}(25 \mathrm{G})$ gauge needles

- $40 \mathrm{mg}$ MPA (I ml)

- I\% lignocaine (l-3 ml)

Tenderness in the illiotibial band syndrome is usually located over the lateral condyle where the band slips backwards and forwards as the knee flexes and extends. The injection should be directed to the site of maximum tenderness. Occasionally there may be swelling due to bursitis under the band, which should also be injected.

\section{Achilles bursitis}

Material

- $5 \mathrm{ml}$ syringe

- $20 \times 0.5 \mathrm{~mm}(25 \mathrm{G})$ gauge needles

- $40 \mathrm{mg}$ MPA (l ml)

- I\% lignocaine ( $\mathrm{I} \mathrm{ml})$

The needle is directed towards the bursa lying anteriorly or posteriorly to the Achilles tendon. Injection into the tendon is strongly contra-indicated due to a high risk of tendon rupture.

Enter the skin on the lateral side of the heel, just above the top of the calcaneum. Direct the needle medially to the pre-achillean bursa or downward to the retroachillean bursa, which lies just beneath the skin (Figure II). Never inject against resistance.

\section{Tarsal tunnel}

Material

- $5 \mathrm{ml}$ syringe

- $20 \times 0.5 \mathrm{~mm}(25 \mathrm{G})$ gauge needles

- $40 \mathrm{mg}$ MPA (I ml)

- I\% lignocaine ( $\mathrm{l} \mathrm{ml})$

Inject under the flexor retinaculum, between the calcaneus and the medial malleolus.

\section{Plantar fasciitis}

\section{Material}

- $5 \mathrm{ml}$ syringe

- $40 \times 0.7 \mathrm{~mm}(22 \mathrm{G})$ gauge needles

- $40 \mathrm{mg}$ MPA (I ml)

- I\% lignocaine ( $1-2 \mathrm{ml})$ 


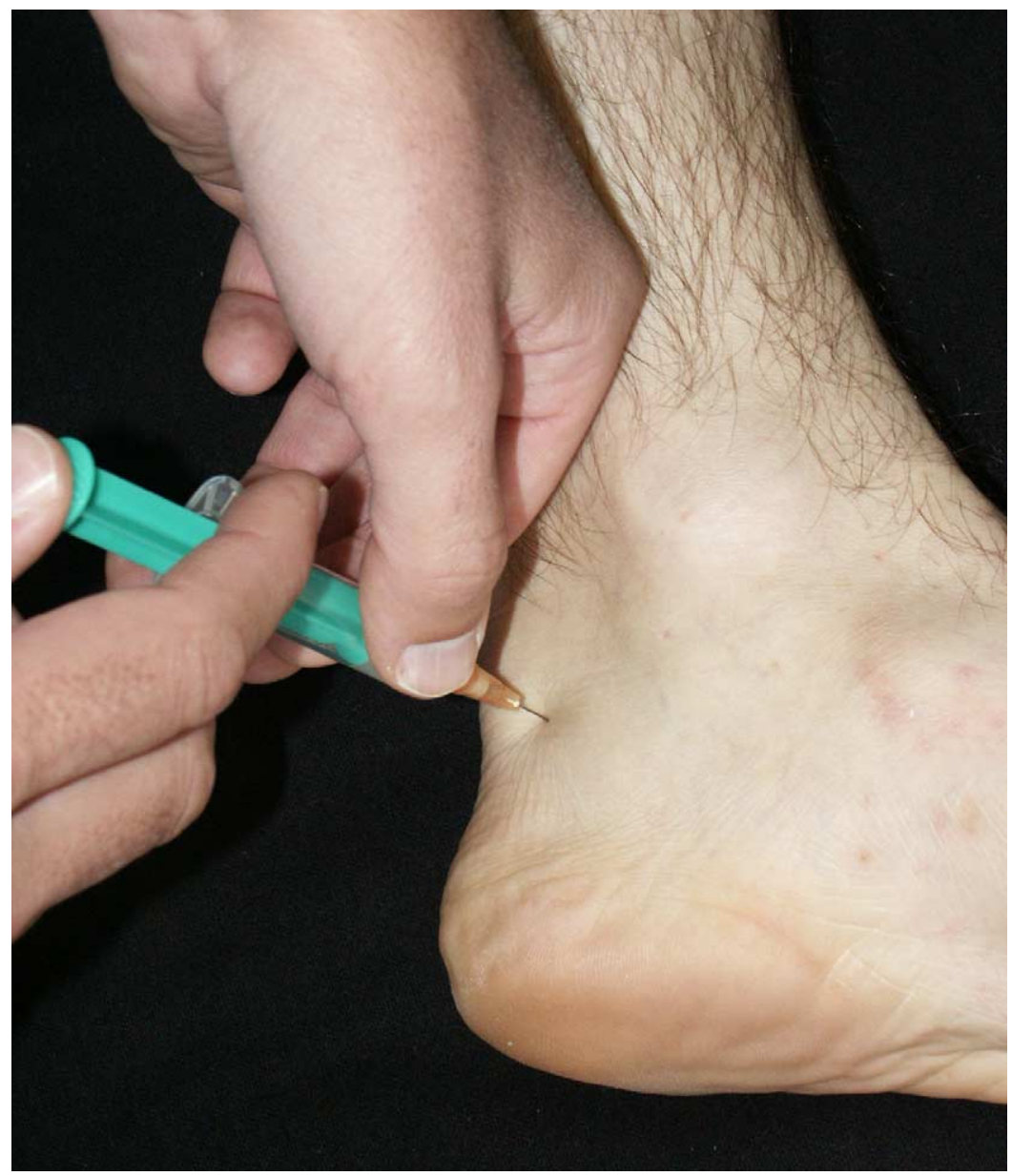

Figure I I. Injection of Achilles bursitis.

Locate the site of maximum tenderness on the plantar surface of the heel. The injection should be placed as close as possible to the insertion of the fascia in the bone. This can be addressed perpendicularly to the plantar skin (25G needle) or via the medial side of the heel ( $22 \mathrm{G}$ needle: Figure I2), so that the injection site lies beneath the tender spot.

\section{Tenosynovitis of the posterior tibialis}

\section{Material}

- $5 \mathrm{ml}$ syringe

- $20 \times 0.5 \mathrm{~mm}(25 \mathrm{G})$ gauge needles

- $40 \mathrm{mg}$ MPA (I ml)

- $\mathrm{l} \%$ lignocaine $(\mathrm{I}-2 \mathrm{ml})$ 


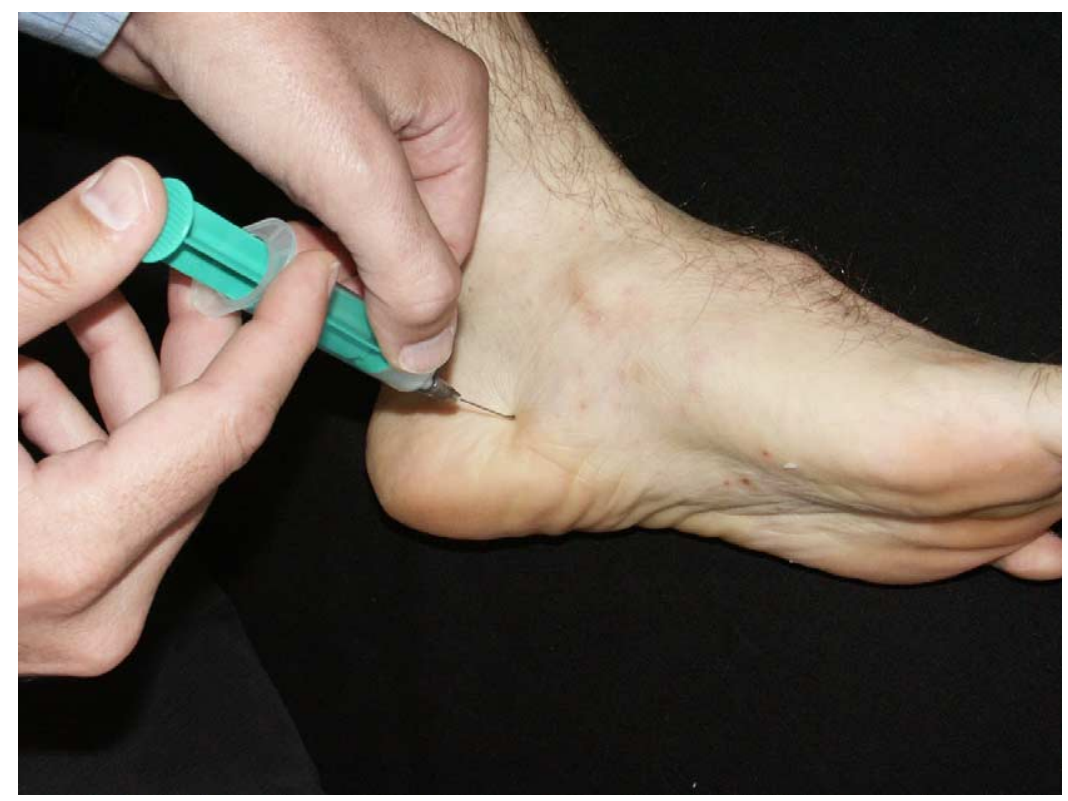

Figure I2. Injection of plantar fasciitis.

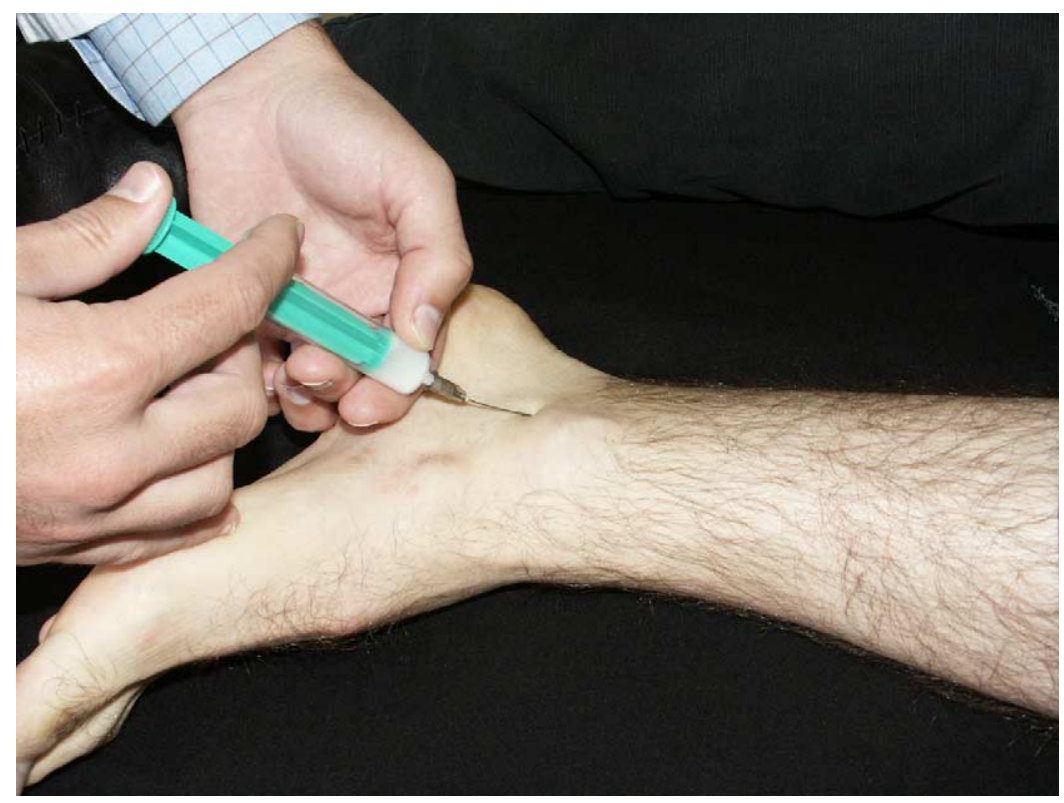

Figure 13. Injection of tenosynovitis of the posterior tibial tendon. 
Palpate the tender tendon sheath posteriorly and distally to the medial malleolus. The needle is inserted towards the leg, on a tangent to the bone (Figure 13). The injection is placed about $\mathrm{I} \mathrm{cm}$ beneath the skin. We find this injection difficult to place precisely and tend to ask for ultrasound guidance.

\section{Morton metatarsalgia}

\section{Material}

- $5 \mathrm{ml}$ syringe

- $20 \times 0.5 \mathrm{~mm}(25 \mathrm{G})$ gauge needles

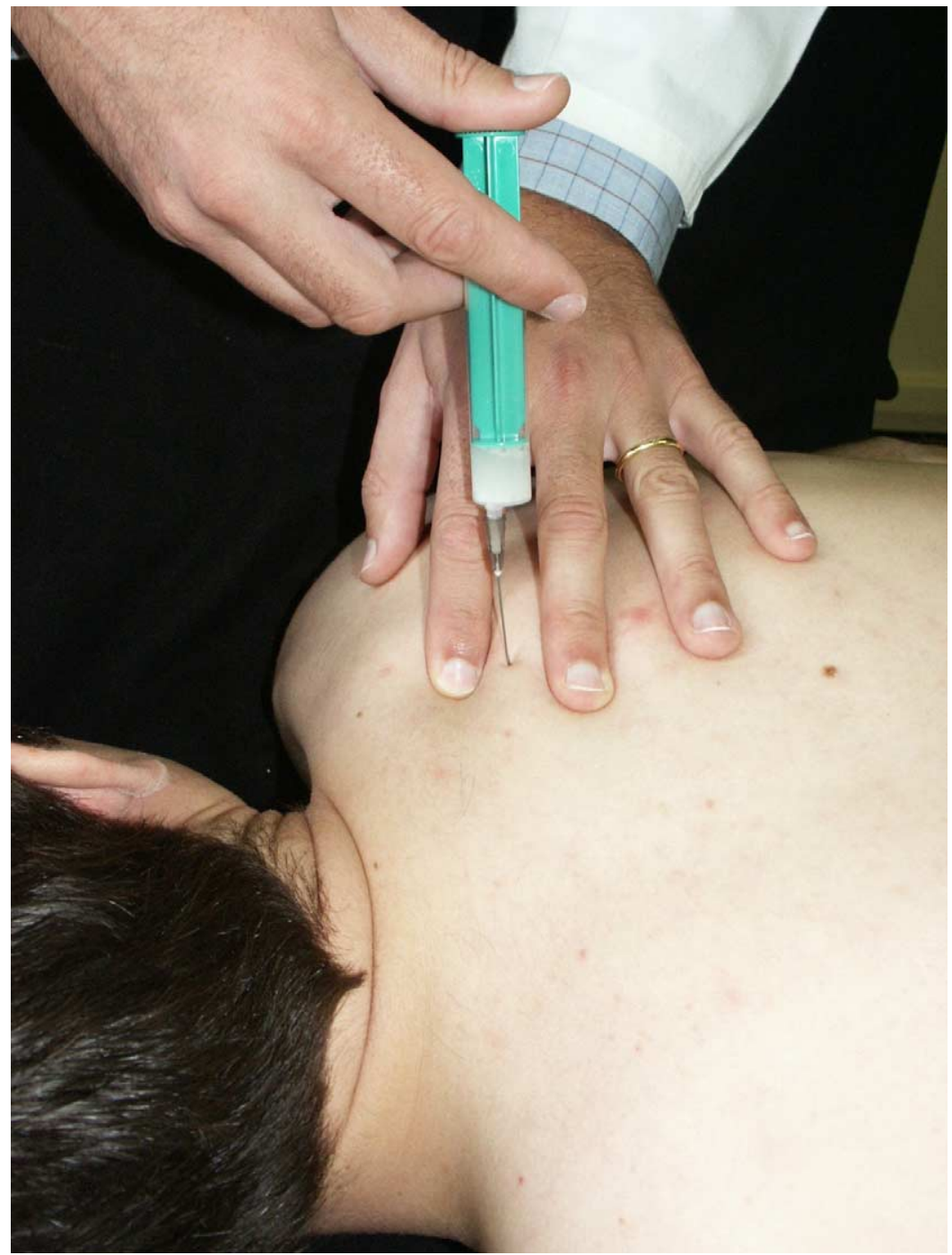

Figure 14. Injection of tender and trigger points. 
- $40 \mathrm{mg}$ MPA (l ml)

- I\% lignocaine (l-2 ml)

The usual recommendations suggest that the injection should be performed in the intermetatarsal space around the site of maximum tenderness.

\section{Tender and trigger points}

Material

- $5 \mathrm{ml}$ syringe

- $40 \mathrm{mg}$ MPA (l ml)

- I\% lignocaine ( $\mathrm{I}-2 \mathrm{ml})$ or dry needling

Tender or trigger points should be carefully identified before insertion of the needle. Ideally a taut band is clearly located and secured between the index and middle finger of one hand. The needle is inserted at an angle of about $45^{\circ}$ to the skin, parallel to the muscle fibres (Figure 14). The injection is placed inside the taut band, using a fan technique if needed.

\section{SUMMARY}

Soft tissue rheumatic disorders are extremely common and result in significant morbidity, loss of productivity and socioeconomic impact.

Early intervention is aimed at resolving the injury and preventing chronicity and recurrence. Soft tissue glucocorticoid injections are commonly reserved for chronic cases. Evidence from histopathological, biochemical and molecular studies do not support a major role for inflammation in soft tissue disorders, undermining the rationale for the use of glucocorticoid injections in these conditions. Although glucocorticoid injections are associated with relief in the short term, evidence to either support or refute their superiority over alternative treatments is scarce, particularly in the long-term. This may reflect the true efficacy of injections or may be due to the lack of adequate studies. There is a clear need for further trials of good methodological quality to settle this question.

The clinical decision to perform a local glucocorticoid injection should be based on a clear diagnosis and careful consideration of the risks, benefits and alternative approaches. The practitioner should have good knowledge of the local anatomy and technical experience of the procedure. Provided that technical recommendations are respected, glucocorticoid injections have few contraindications and are safe procedures

\section{Practice points}

- scientific evidence does not support a major role for inflammation in soft tissue rheumatism and hence the rationale for the use of glucocorticoid injections for its treatment 
- studies on the efficacy of glucocorticoid injections are limited in number and quality

- overall, local soft tissue injections are associated with short-term benefit but uncertain long-term results

- local injection should be based, as much as possible, on a clear diagnosis and careful consideration of the risks, benefits and alternative approaches

- soft tissue glucocorticoid injections are usually reserved for chronic cases, after the failure of other conservative measures.

- glucocorticoid injections have few contraindications and are very safe, provided that technical recommendations are respected.

\section{Research agenda}

- progress in this area will demand considerable refinement in the methodology of clinical trials, including a careful definition of cases and endpoints

- further controlled studies of good methodological quality are needed to establish the true efficacy of glucocorticoid injections, especially in the longer term

- studies designed to evaluate the relevance of glucocorticoid type and dose, post-injection rest and other technical details should be encouraged

- research is needed to establish the value of MRI and ultrasonography as means of improving injection efficacy, through improved diagnosis and injection guidance

\section{REFERENCES}

*I. Riley G. The pathogenesis of tendinopathy. A molecular perspective. Rheumatology 2004; 43: I3I-|42.

2. Hyman J \& Rodeo SA. Injury and repair of tendons and ligaments. Physical Medicine and Rehabilitation Clinics of North America 2000; I I: 267-288.

3. Speed CA. Corticoglucocorticoid injections in tendon lesions. British Medical Journal 200 I; 323: 382-386.

4. Józsa $L$ \& Kannus $P$. Overuse injuries of tendons. In Józsa $L$ \& Kannus $P$ (eds.) Human Tendons: Anatomy, Physiology and Pathology. New York: Human Kinetics, 1997, pp. 164-253.

5. Leadbetter KB. Cell matrix response in tendon injury. Clinical Sports Medicine 1992; I I: 533-578.

6. Curwin SL. The aetiology and treatment of tendinitis. In Harries M, Williams C, Stannish WD \& Micheli LJ (eds.) Oxford Textbook of Sports Medicine. Oxford: Oxford University Press, 1994, pp. 5I2-528.

7. Josza J \& Kannus P. Treatment principles in tendon injuries and other tendon disoders. In Józsa $L$ \& Kannus P (eds.) Human Tendons: Anatomy, Physiology and Pathology. New York: Human Kinetics, 1997, pp. 49I-525.

*8. Buchbinder R, Green S \& Youd JM. Corticoglucocorticoid injections for shoulder pain. Cochrane Database Systematic Reviews 2003; I: CD0040I6.

9. Kannus $P$, Jarvinen M \& Niitymaki S. Long- or short-acting anesthetic with corticoglucocorticoid in local injections of overuse injuries? A prospective, randomised, double-blind study. International Journal of Sports Medicine 1990; I I: 397-400. 
10. Canoso JJ. Aspiration and injection of joints and periarticular tissues. In Klippel JH \& Dieppe PA (eds.) Rheumatology. London: Mosby, 1998, pp. 2.12.1-2.12.11.

* II. Marshall S, Tardif G \& Ashworth N. Local corticoglucocorticoid injection for carpal tunnel syndrome. Cochrane Database Systematic Reviews 2002; 4: CD00I554.

* 12. Eustace JA, Brophy DP, Gibney RP et al. Comparison of the accuracy of glucocorticoid placement with clinical outcome in patients with shoulder symptoms. Annals of the Rheumatic Diseases 1997; 56: 59-63.

13. Balint $P$ \& Sturrock RD. Musculoskeletal ultrasound imaging: a new diagnostic tool for the rheumatologist? British Journal of Rheumatology 1997; 36: I |4I-I I 42.

14. Koski JM. Ultrasound guided injections in rheumatology. Journal of Rheumatology 2000; 27: 2I3I-2I38.

15. Adler RS \& Sofka CM. Percutaneous ultrasound-guided injections in the musculoskeletal system. Ultrasound Quarterly 2003; 19: 3-12.

* 16. Naredo E, Cabero F, Beneyto $\mathrm{P}$ et al. A randomized comparative study of short term response to blind injection versus sonographic-guided injection of local corticoglucocorticoids in patients with painful shoulder. Journal of Rheumatology 2004; 3 I: 308-3I4.

17. Adebajo A, Nash P \& Hazleman B. A prospective double blind dummy placebo controlled study comparing triamcinolone hexacetonide injection with oral diclofenac in patients with rotator cuff tendonitis. Journal of Rheumatology 1990; 17: 1207-1210.

18. Blair B, Rokito AS, Cuomo F, Jarolem K \& Zuckerman JD. Efficacy of injections of corticoglucocorticoids for subacromial impingement syndrome. Journal of Bone and Joint Surgery 1996; 78: 1685-1689.

19. Kirkley A, Litchfield R, Alvarez $C$ et al. Prospective double blind randomised clinical trial of subacromial injection of betamethasone and xylocaine versus xylocaine alone in rotator cuff tendinosis. Journal of Bone and Joint Surgery 1999; 8 I B(supplement I): 107.

*20. Petri M, Dobrow R, Neiman R et al. Randomised double blind placebo controlled study of the treatment of the painful shoulder. Arthritis and Rheumatism 1987; 30: 1040-1045.

21. Plafki C, Steffen R, Willburger RE \& Wittenberg RH. Local anaesthetic injection with and without corticoglucocorticoids for subacromial impingement syndrome. International Orthopedics 2000; 24: 4042.

22. Strobel G. Therapeutic effects of an injection of either mepivacaine hydrochloride (MVH) or of a combination of $\mathrm{MVH}$ and triamcinolone hexacetonide in chronic periarticular disorder of the shoulder with regard to pain, mobility, and working ability. Rehabilitation 1996; 35: 176-178.

23. Vecchio PC, Hazleman BL \& King RH. A double-blind trial comparing subacromial methylprednisolone and lignocaine in acute rotator cuff tendonitis. British Journal of Rheumatology 1993; 32: 743-745.

24. White R, Paull D \& Fleming K. Rotator cuff tendonitis: comparison of subacromial injection of long acting corticoglucocorticoid versus indomethacin therapy. Journal of Rheumatology 1986; 13: 608-6I3.

*25. Assendelft WJJ, Hay EM, Adshead R \& Bouter LM. Corticoglucocorticoid injections for lateral epicondylitis: a systematic overview. British Journal of General Practice 1996; 46: 209-216.

26. Hay EM, Paterson SM, Lewis M et al. Pragmatic randomised controlled trial of local corticoglucocorticoid injection and naproxen for treatment of lateral epicondylitis of elbow in primary care. British Medical Journal 1999; 31 9: 964-968.

27. Weinstein P, Canoso J \& Wohlgethan JR. Long-term follow-up of corticoglucocorticoid injection for traumatic olecranon bursitis. Annals of Rheumatic Diseases 1984; 43: 44-46.

28. Anderson BC, Manthey R \& Brouns MC. Treatment of De Quervain's tenosynovitis with corticoglucocorticoids. A prospective study of the response to local injection. Arthritis and Rheumatism I991; 34: 793-798.

29. Lambert MA, Morton RJ \& Sloan JP. Controlled study of the use of local glucocorticoid injection in the treatment of trigger finger and thumb. Journal of Hand Surgery 1992; I7B: 69-70.

30. Murphy D, Falla JM \& Koniuch MP. Steroid versus placebo injection for trigger finger. Journal of Hand Surgery 1995; 20A: 628-631.

31. Anderson B \& Kaye S. Treatment of flexor tenosynovitis of the hand ('trigger finger') with corticoglucocorticoids. A prospective study of the response to local injection. Archives of Internal Medicine 199I; I5 I: I53-156.

32. Dammers JWHH, Veering MM \& Vermeulen M. Injection with methylprednisolone proximal to the carpal tunnel: randomised double blind trial. British Medical Journal 1999; 319: 884-886. 
33. Celiker R \& Inanici AS. Corticoglucocorticoid injection vs nonglucocorticoidal antiinflammatory drug and splinting in carpal tunnel syndrome. American Journal of Physical Medicine and Rehabilitation 2002; 81 : 182186.

34. Gelberman RH, Aronson D \& Weisman M. Carpal tunnel syndrome: results of a prospective trial of glucocorticoid injection and splinting. Journal of Bone and Joint Surgery 1980; 62: ||8|-| | 84.

35. Shbeeb M, O'Duffy D, Michet CJ et al. Evaluation of glucocorticoglucocorticoid injection for the treatment of trochanteric bursitis. Journal of Rheumatology 1996; 23: 2104-2106.

36. DaCruz DJ, Geeson M, Allen MJ \& Phair I. Achilles' paratendonitis: an evaluation of glucocorticoid injection. British Journal of Sports Medicine 1988; 22: 64-65.

37. Berger RG \& Yount WJ. Immediate 'glucocorticoid flare' from intraarticular triamcinolone hexacetonide injection: case report and review of the literature. Arthritis and Rheumatism 1990; 33: 1284-1286.

38. Gray RG, Tenenbaum J \& Gottlieb NL. Local corticoglucocorticoid injection treatment in rheumatic disorders. Seminars on Arthritis and Rheumatism 1981; 10: 231-254.

39. Charalambous CP, Tryfonidis M, Sadiq S, Hirst P \& Paul A. Septic arthritis following intra-articular glucocorticoid injection of the knee-a survey of current practice regarding antiseptic technique used during intra-articular glucocorticoid injection of the knee. Clinical Rheumatology 2003; 22: 386-390.

40. Speed CA. Injection therapies for soft-tissue disorders. Best Practice and Research Clinical Rheumatology 2003; 17: 167-181.

4I. Genovese MC. Joint soft-tissue injection. A useful adjuvant to systemic and local treatment. Postgraduate Medicine 1998; 103: 125-134.

42. Doherty M, Hazleman BL, Hutton CW, Maddison PJ \& Perry JD. Rheumatology Examination and Injection Techniques. Ist edn. London: W.B. Saunders Company Ltd; 1992.

43. Sheon RP, Moskowitz RW \& Goldberg VM. Soft Tissue Rheumatic Pain: Recognition, Management and Prevention. 3rd edn. Baltimore: Williams and Wilkins; 1996.

44. Dixon ASJ \& Emery P. Local injection therapy in rheumatic diseases. 4th edn. Basle: Eular Publishers; 1992.

45. Rifat SF \& Moeller JL. Basics of joint injection. General techniques and tips for safe, effective use. Postgraduate Medicine 200I; 109: 156-157.

46. Rifat SF \& Moeller JL. Site-specific techniques of joint injection. Useful additions to your treatment repertoire. Postgraduate Medicine 200 I; 109: I23-130 [see also pages I35-|36].

47. Zingas C, Failla JM \& Van Holsbeeck M. Injection accuracy and clinical relief of de Quervain's tendinitis. Journal of Hand Surgery (Am) 1998; 23: 89-96. 